\title{
Development of a Patient-Doctor Communication Skills Model for Medical Students
}

Young Hee Lee and Young-Mee Lee

Department of Medical Education, Korea University College of Medicine, Seoul, Korea

\section{의대생을 위한 환자-의사 커뮤니케이션 모델 개발}

고려대학교 의과대학 의학교육학교실

\section{이영희, 이영미}

Purpose: Communication is a core clinical skill that can be taught and learned. The authors intended to develop a patient-doctor communication model for teaching and assessing undergraduate medical students in Korea.

Methods: To develop a model, literature reviews and an iterative process of discussion between faculty members of a communication skills course for second year medical students were conducted. The authors extracted common communication skill competencies by comparing the Kalamazoo Consensus Statement, SEGUE framework communication skills, the Calgary Cambridge Observation Guides, and previous communication skills lists that have been used by the authors. The content validity, with regard to clinical importance and feasibility, was surveyed by both faculty physicians and students.

Results: The first version of the model consisted of 36 items under 7 categories: initiating the session (8 items), building a relationship (6), gathering information (8), understanding a patient's perspectives (4), sharing information (4), reaching an agreement (3), and closing the session (3). It was used as a guide for both students and teachers in an actual communication skills course. At the end of the course, student performance was assessed using two 7-minute standardized patient interviews with a 34-item checklist. This assessment tool was modified from the first version of the model to reflect the case specificity of the scenarios. A patient-doctor communication model, which can be taught to those with limited patient care experience, was finally developed.

Conclusion: We recommended a patient-doctor communication skills model that can be used for teaching and evaluating preclinical and clinical students. Further studies are needed to verify its validity and reliability.

Key Words: Physician-patient relations, Communication, Medical students

서론

의사와 환자 간의 효과적인 커뮤니케이션은 의학지식 및 기
술과 마찬가지로 진료에 있어 기본적 능력으로 인식되고 있 다. 선행연구들은 의사의 커뮤니케이션 능력이 진료만족도 및 순응도에 영향을 미치는 주요 요인으로 작용하며 궁극적 으로 진료 결과와 건강증진에 긍정적 영향이 있음을 보고하
Received: May 24, 2010 • Revised: June 29, 2010 • Accepted: June 30, 2010 Corresponding Author: Young-Mee Lee

Department of Medical Education, Korea University College of Medicine, 126-1 Anam-dong 5-ga, Seongbuk-gu, Seoul 136-705, Korea

Tel: +82.2.920.6098 Fax: +82.2.928.1647 email: ymleehj@korea.ac.kr
Korean J Med Educ 2010 Sep; 22(3): 185-195. doi: $10.3946 /$ kjme.2010.22.3.185. pISSN: 2005-727X eISSN: 2005-7288

(C) The Korean Society of Medical Education. All rights reserved. This is an open-access article distributed under the terms of the Creative Commons Attribution Non-Commercial License (http:// creativecommons.org/licenses/by-nc/3.0/), which permits unrestricted non-commercial use, distribution, and reproduction in any medium, provided the original work is properly cited. 
Young Hee Lee and Young-Mee Lee: Development of a Patient-Doctor Communication Skills Model for Medical Students

였다[1,2,3]. 또한 커뮤니케이션 능력은 학습을 통하여 습득 되고 향상될 수 있음을 입증하는 연구들이 제시되면서[4], 세 계 각국의 학부 의학교육 및 졸업 후 의학교육 단체에서는 환 자와의 신뢰적 관계 형성에 기초가 되는 커뮤니케이션 기술 을 반드시 교육하고 훈련하도록 권장하고 있다[5,6,7].

미국의과대학협의회(The Association of American $\mathrm{Me}^{-}$ dical Colleges, AAMC)는 모든 의과대학이 임상 역량강화를 위한 교육과정의 일부로서 커뮤니케이션을 교육하고 평가할 것을 권고한 바 있다[5]. 또한 전공의교육인증위원회(The Accreditation Council for Graduate Medical Education, $\mathrm{ACGME}$ )는 모든 전공의들이 갖추어야 할 핵심 임상기술로 커뮤니케이션을 교육하고 평가하도록 권장하고 있다[6].

국내에서도 의료인의 커뮤니케이션 능력 계발의 중요성이 강조되면서 2007년 Korea Medical School Information System (KOMSIS) 자료에 의하면 전국 41개 의과대학 및 의 학전문대학원 중 $88 \%$ (36개교)가 커뮤니케이션 교과과정을 개설·운영하고 있다[8]. 그러나 국내 의료 커뮤니케이션 교 육은 도입 초기단계로서 교육과정, 교수방법, 대학의 재정적 지원 등 여러 방면에서 지속적 향상이 요구되고 있으며 교육 효과에 대한 평가도 아직 미흡하다.

의료 커뮤니케이션 교육과 평가가 체계적으로 시행되기 위 해서는 의과대학생에게 필수적으로 가르쳐야 할 커뮤니케이 션의 요소에 대한 파악과 이를 토대로 한 표준적인 모델이 필 요하다. 표준적 모델은 의료커뮤니케이션 교육과정의 학습목 표와 내용 선정에 가이드를 제공하고 학생 성취도 평가의 근 거가 되며 교육과정의 목표 달성도를 평가하고 개선하는데 필요하다. 또한 이는 교수들의 전공분야나 환자 진료 스타일 에 따른 교육수준과 내용의 편차를 줄이고 좀 더 일관성 있게 학생들을 지도할 수 있기 때문에 중요하다.

미국이나 유럽의 의료선진국에서는 학부에서 졸업 후 의학 교육을 통해 가르치고 평가해야 할 핵심 커뮤니케이션 기술 들에 대한 논의와 교육모형에 대하여 논의가 오래 전부터 있 었다. 대표적인 예로 Toronto 합의[9], SEGUE Framework for teaching and assessing communication skills (이하 SEGUE Framework) [10], Calgary-Cambridge Observation Guide (이하 CCOG) [11], Kalamazoo Consensus [12], ACGME의 Outcome Projects 2001 [13] 등이 있다. 국내에
서는 외국의 대표적인 의료 커뮤니케이션 모형을 수정, 번안 하여 교육에 활용하고 있지만[14], 이러한 모형에서 제시하는 요소들이 국내 의료현실에서도 반드시 필요하고 실제로 수행 가능한 것인지에 대해서는 체계적 검토가 부족하다. 또한 번 안된 외국의 의료커뮤니케이션 모형이 환자진료 경험이 거의 없는 임상실습 전 학생 교육에 있어 적합한 것인지에 대한 검 토 역시 미흡하다.

이에 연구자들은 국내 의과대학에서 학생들 교육에 적용할 수 있는 환자-의사 커뮤니케이션 모델을 개발하고자 하였다. 이는 일차적으로 커뮤니케이션 수업 설계 및 조직을 위한 기 초를 제공하며 학생들이 수업을 통해 성취해야 할 수행의 목 표를 제시한다. 또한 학생들의 학업성취도의 준거로 활용되 며 학생들 스스로 자신들의 의사소통능력 향상 정도를 평가 하고 성찰하기 위한 자가 평가 도구로 사용될 수 있다. 이 논 문에서는 환자-의사 커뮤니케이션 모델 개발 과정과 저자들 이 개발한 모델을 일개 대학 의료커뮤니케이션 수업에 적용 한 사례를 기술하고자 한다.

\section{대상 및 방법}

\section{1. 환자-의사 커뮤니케이션 모델 개발팀 구성}

개발팀은 의과대학에서 커뮤니케이션 수업에 참여하고 있 는 교수진으로서 의학교육학, 교육심리 및 평가, 가정의학과 의사를 포함한 총 4 인으로 구성하였다. 개발팀은 선행연구 문 헌 분석, 기존 커뮤니케이션 교육 모델 비교 분석, 전문가 자 문결과 토론, 개발한 커뮤니케이션 모델 적용 후 분석 등에 참 여하였다.

\section{2. 문헌검토와 선행모델 비교 분석}

연구자들은 문헌검토를 시행하였고 국외 선행 연구 중 SEGUE Framework, CCOG, Kalamazoo Consensus [10,11,12]의 3개 모델과 저자들의 대학에서 2006 2007년 의 학과 학생들을 대상으로 교육과 평가에 활용하였던 커뮤니케 이션 가이드를 비교 분석하여 대차대조표를 작성한 후 공통 요소를 추출하였다. 
Fig. 1. The Overall Process of the Patient-Doctor Communication Skills Model

Planning $\begin{aligned} & \text { Developing } \\ & \text { patient-doctor } \\ & \text { communication skills } \\ & \text { model (first version) }\end{aligned}\left|\begin{array}{l}\text { Review by } \\ \text { expert } \\ \text { panel }(10 \\ \text { physicians } \\ \text { faculty) }\end{array}\right| \begin{aligned} & \text { Application } \\ & \text { - Teaching } \\ & \text { - Assessment } \\ & \text { - Student's } \\ & \text { self-evaluation }\end{aligned}\left|\begin{array}{l}\text { A patient-doctor } \\ \text { communication skills } \\ \text { model was finalized }\end{array}\right|$

\section{3. 전문가 자문 의뢰}

연구자들이 개발한 환자-의사 커뮤니케이션 모델(초안)에 서 제시하는 커뮤니케이션 요소들이 실제 의사 혹은 미래의 의사가 될 의대생에게 반드시 필요한 자질인지와 교육 후 습 득 여부에 대한 평가가 가능한지를 검토하기 위하여 전문가 자문을 시행하였다.

전문가 자문에는 실제 의료커뮤니케이션 수업에 참여한 경 험이 있는 임상교수 10 명(내과 3 명, 가정의학과 2 명, 응급의 학과 1 명, 정형외과 1 명, 정신과 1 명, 마취통증의학과 1 명, 핵 의학과 1 명)이 참여하였다.

전문가들은 환자-의사 커뮤니케이션 모델(초안)의 각 항목 에 대하여 꼭 필요한 커뮤니케이션 요소인지와 관찰과 평가 가 가능한 항목인지를 평가하였다. 즉, 전문가들은 각 항목에 대하여 '진료 시 의사가 할 수 있어야 하는 핵심기술인지', ‘학 생들이 습득해야 하는 핵심기술인지', '교수가 학생들의 수행 능력을 평가하기에 적합한 것인지', '의학과 2학년 학생들이 자가 평가할 수 있는 것인지'의 총 4가지 질문에 대하여 검토 하였다. 그 밖에 단어 또는 표현이 부적절하거나 모호한 부분 있는지 또는 기타 개선 사항이 있는지를 검토하였다.

전문가 자문은 다른 평가자로부터 영향을 받지 않도록 하 기 위하여 개별적으로 전자메일을 통하여 이루어졌다. 각 항 목이 핵심기술인지에 대한 평가는 5점 리커트 척도(1: 전혀 중요하지 않음, 2: 별로 중요하지 않음, 3: 그저 그럼, 4: 어느 정도 중요함, 5: 매우 중요함)를 사용하였고, 평가도구로서의 적절성 여부는 '예' 또는 '아니오'로 답하게 하였다. 자문가가 검토한 내용의 분석은 SPSS win 12.0 (SPSS Inc., Chicago, USA)을 이용하여 빈도분석 및 기술통계량을 산출하였다.

\section{4. 환자-의사 커뮤니케이션 모델의 수업 적용}

전문가 자문 결과를 반영하여 환자-의사 커뮤니케이션 모 델을 일차적으로 완성하였고 2008년 2학기 고려대학교 의과 대학 의학과 2 학년에 개설된 '의료대화' 수업에 교육 및 평가 도구로 적용하였다. 즉, 개발한 모델은 학생 및 교수에게 수업 의 목표와 내용을 알려주는 가이드와 피드백의 기준으로 활 용되었다(Table 1 의 36 개 항목). 또한 학생들에게도 모델의 각 요소가 의사가 수행할 수 있어야 하는 중요한 임상자질인 지와 각 요소에 대한 수행 자신감을 수업 전후 설문을 시행함 으로써 학생들의 자기성찰의 기회를 제공하였다. 또한 개발 한 모델을 표준화 환자 면담 실기시험의 평가도구로써 적용 해보고 수업과 평가 도구로서의 활용가능성을 확인하였다.

이상에서 기술한 전반적인 연구진행 절차를 요약하면 Fig. 1 과 같다.

\section{결과}

\section{1. 환자-의사 커뮤니케이션 모델 개발}

\section{1) 환자-의사 커뮤니케이션 모델(초안) 개발}

모델의 전체적인 구성은 Kalamazoo의 7개 분류 체계에 따 라 면담시작, 관계수립, 정보수집, 환자관점이해, 정보공유, 합의도달, 면담종료의 7개 영역으로 구성하였다. 각 영역의 세부항목은 SEGUE Framework, COCG, Kalamazoo Consensus, 2006년과 2007년도 '의료대화수업에 사용했던 체크 리스트의 대차대조표 비교에서 공통적인 요소를 추출하여 총 36 개 문항으로 구성된 모델 초안을 개발하였다(Table 1 의 36 항목).

첫째, '면담시작' 영역은 환영인사, 환자의 이름 확인, 학생의 
사의 이름 소개, 학생의사 역할 소개, 관심과 존중 표현, 환자 의 방문 이유 확인, 환자가 처음 하는 말을 끊지 않고 들어주기, 면담의 목표 조정 및 설명 등 총 8개 문항으로 구성하였다. 둘째, '관계수립' 영역은 면담 시작에서 마무리까지 면담기 간 동안 지속적으로 표현해야 하는 언어적, 비언어적 기술로 서 환자와 정서적 공감과 신뢰를 형성하고 협력적 관계를 이 루는데 도움을 주는 문항들을 포함하고 있다. 즉, 상황에 적절 한 비언어적 행동표현, 환자의 말 중단하지 않고 듣기, 환자의 주요 관심사와 정보에 대하여 주의집중 유지하기, 공감함을 말로 표현하기, 환자의 말 반복해주기, 환자가 말한 사실과 감 정에 대한 재진술의 6 개 항목이다.

셋째, '정보수집' 영역은 환자의 문제와 병력, 관련 심리 사 회적 문제 등을 효과적으로 수집하는 데 필요한 요소들로 구 성하였다. 즉, 개방형 및 폐쇄형 질문의 균형적 사용, 요약하 기, 명료화하기, 환자의 부가적 질문이나 정보 확인하기, 심리 사화환경적 요인 질문하기, 주제 전환을 알리거나 이유 설명 하기, 신체검사 통보하기, 논리적 순서로 면담하기의 8개 항 목이다.

넷째, '환자의 관점 이해'는 환자 중심적 접근을 반영한 문 항으로 문제나 질병에 대한 환자의 생각 질문하기, 문제에 대 한 환자의 감정 파악, 환자의 생각과 감정을 학생의사가 수용 하고 있음을 말로 표현하기, 진단과 치료에 대한 환자의 기대 와 선호도 파악하기의 4 개 문항을 포함하고 있다.

다섯째, '정보공유' 영역은 환자의 요구를 정확히 파악하고 수준에 맞는 정보를 쉽게 제공하는 데 필요한 기술들이다. 즉, 환자가 이해하기 쉬운 말과 용어로 설명하기, 환자의 이해도 확인, 추가적 설명이나 정보가 필요한지 질문하기, 환자의 요 구와 수준에 맞게 정보 제공하기 등의 4 개 항목이다.

여섯째, '합의도달' 영역은 환자의 의견과 선호를 고려하여 환자와 의사가 동의할 수 있는 치료계획을 수립하는 데 필요한 기술로서 환자의 주변 자원 파악하기, 환자의 의견 반영하여 합의점 도출하기, 의사가 제시한 진료방침에 동의하는지 질문 하기의 3 개 항목으로 구성되었다.

마지막으로 '면담종료'에서는 추가질문이나 걱정거리 파악, 전체 면담과정에 대한 요약, 차기 진료 약속이나 계획 설명의 3 개 문항을 포함하였다.

\section{2) 전문가 검토 결과}

위에서 개발한 환자-의사 커뮤니케이션 모델(초안)의 항목 들이 의사 또는 학생들이 갖추어야 할 핵심기술인지와 객관 적 평가가 가능한 것인지를 확인하기 위하여 자문가 자문을 시행하였고 그 결과는 Table 1과 같다.

'의사가 갖추어야 할 핵심기술에서 문항별 평균 점수는 최소 3.4점에서 최대 4.9점이었다. 평균점수가 4점 이하인 항목은 8 개였으나, 1 개 항목(22번 논리적 순서에 따라 면담 진행하기) 을 제외한 나머지 35개 항목은 모두 평균점수가 3.5점 이상이 었다. 그 중 특히 평균점수가 4.0점 이상으로 필요성을 높게 평가한 항목은 총 28개였다. '학생이 습득해야 할 핵심기술인 지에 대해서는 20 번 항목(주제 전환을 알리거나 이유 설명하 기)이 평균 3.8점, 31번 항목(진료에 필요한 자원 파악하기)이 평균 3.9점으로 4점 미만이었으며, 나머지 항목은 모두 평균 4.0점 이상으로 36 개 항목 모두에 대하여 학생들이 배워야 할 핵심기술로 필요성을 높게 인식하고 있음을 알 수 있었다.

'평가도구로서의 적절성'에 대한 검토에서 '교수가 학생들의 수행능력을 평가하기에 적합한 것인지'에 대해서는 26개 문항 에 대해 70\% 이상의 자문가가 '적절하다'고 응답했다. $50 \%$ 이 상의 전문가가 '적절치 않다는 의견을 제시한 문항은 모두 8 개로서 10 번(면담기간 동안 환자의 말을 끊지 않고 들어주 기), 11 번(환자의 주요 관심사 혹은 정보를 관심을 가지고 들 어주기), 14 번(환자의 말에 내포되어 있는 내용과 감정에 대 해 재진술하기), 15 번(개방형 질문과 폐쇄형 질문을 균형적으 로 사용하기), 22번(논리적 순서에 따라 면담 진행하기), 24번 (문제나 질병에 대한 환자의 생각 또는 감정을 말할 수 있도 록 격려하기), 26 번(진단과 치료에 대한 환자의 기대 및 선호 도 파악하기), 30 번(환자의 요구와 수준에 맞게 정확한 정보 제공하기) 항목이었다. '의학과 2학년 학생들이 평가할 수 있 는 것인지'에 대해서 $70 \%$ 이상의 전문가가 '그렇다'고 응답한 항목은 총 28개였으며, 5 개 문항(8번, 10번, 11번, 14번, 24 번)에 대해서는 $50 \%$ 이상의 자문가가 적절치 않다는 의견을 제시하였다.

평가자가 교수 또는 학생이거나 상관없이 공통적으로 50\% 이상의 자문가가 ‘평가하기에 적절하지 않다고 평가한 문항 은 총 4개로서 10 번(면담기간 동안 환자의 말을 끊지 않고 들 어주기), 11 번(환자의 주요 관심사 혹은 정보를 관심을 가지 
Table 1. An Expert Panel Review for the Initial Communication Skills Model in Terms of Teaching and Assessment

\begin{tabular}{|c|c|c|c|c|}
\hline \multirow{3}{*}{ Items } & \multicolumn{2}{|c|}{$\begin{array}{l}\text { Essential communication skills } \\
\text { achieved by }\end{array}$} & \multicolumn{2}{|c|}{ Measurable by } \\
\hline & Doctors & Students & Teacher & Student \\
\hline & Mean (SD) & Mean (SD) & $\begin{array}{c}\text { Yes/ } \\
\text { Total } \\
\end{array}$ & $\begin{array}{c}\text { Yes/ } \\
\text { Total }^{\text {al }} \text { INS }\end{array}$ \\
\hline 1. Greet patient appropriately & $4.5(0.85)$ & $4.6(0.70)$ & $10 / 10$ & $9 / 10$ \\
\hline 2. Ask and confirm patient's name & $4.9(0.32)$ & $4.9(0.32)$ & $9 / 10$ & $8 / 10$ \\
\hline 3. Introduce (student) doctor's name & $3.7(1.10)$ & $4.3(0.68)$ & $9 / 10$ & $7 / 10(1)$ \\
\hline 4. Explain (student) doctor's role & $3.5(0.71)$ & $4.1(0.88)$ & $9 / 10$ & $7 / 10(1)$ \\
\hline 5. Show interest and respect & $4.6(0.70)$ & $4.6(0.52)$ & $10 / 10$ & $9 / 10(1)$ \\
\hline 6. Identify and confirm problems/issues using open-ended question & $4.6(0.52)$ & $4.8(0.42)$ & $10 / 10$ & $8 / 10(1)$ \\
\hline 7. Listen attentively without interrupting patient's first statement & $4.1(0.99)$ & $4.5(0.71)$ & $7(2) / 10$ & $6 / 10(2)$ \\
\hline 8. Set and/or negotiate an agenda for the talk & $4.6(0.52)$ & $4.2(1.20)$ & $7 / 10$ & $5 / 10(1)$ \\
\hline 9. Demonstrate appropriate non-verbal behaviors & $4.8(0.42)$ & $4.7(0.48)$ & $8 / 10$ & $6 / 10(1)$ \\
\hline 10. Attentively listen to patients' statements without interruption & $3.8(0.92)$ & $4.3(0.68)$ & $5 / 10$ & $4 / 10$ \\
\hline 11. Maintain attentive listening for patient's main issues and information & $3.9(1.10)$ & $4.1(0.99)$ & $4 / 10$ & $5 / 10$ \\
\hline 12. Express empathy using verbal statements & $4.4(0.70)$ & $4.5(0.53)$ & $8 / 10$ & $8 / 10$ \\
\hline 13. Repeat patient's words or echoing & $4.0(0.67)$ & $4.2(0.79)$ & $9 / 10$ & $8 / 10$ \\
\hline 14. Paraphrase patient's statement (paraphrasing) & $3.9(0.74)$ & $4.1(0.74)$ & $5 / 10$ & $5 / 10$ \\
\hline 15. Balanced use of open and close ended questions & $4.0(0.94)$ & $4.2(0.92)$ & $5 / 10$ & $6 / 10$ \\
\hline 16. Summarize patient's statements & $3.9(0.57)$ & $4.2(0.63)$ & $9 / 10$ & $10 / 10$ \\
\hline 17. Clarify patient's statements & $4.3(0.68)$ & $4.2(0.92)$ & $6 / 10$ & $8 / 10$ \\
\hline 18. Allow patients to state additional information or question & $4.4(0.70)$ & $4.6(0.52)$ & $10 / 10$ & 10/10 \\
\hline 19. Discuss psycho-social issues & $4.3(0.68)$ & $4.3(0.68)$ & $7 / 10$ & $8 / 10$ \\
\hline 20. Use transitional statements & $3.7(0.48)$ & $3.8(0.42)$ & $9 / 10$ & $8 / 10$ \\
\hline 21. Orient and explain physical examination in advance & $4.3(0.68)$ & $4.7(0.48)$ & $10 / 10$ & 10/10 \\
\hline 22. Structure interview in logical sequence & $3.4(0.97)$ & $4.0(1.30)$ & $5 / 10$ & $7 / 10$ \\
\hline 23. Elicit patient's views of health problemlideas, concerns) & $4.3(0.95)$ & $4.3(0.95)$ & $6 / 10$ & $8 / 10$ \\
\hline 24. Explores influence of patient's problem or disease on his/her life & $4.2(0.79)$ & $4.2(0.92)$ & $5 / 10$ & $5 / 10$ \\
\hline 25. Show acceptance or acknowledgement patient's idea or emotion & $4.3(0.68)$ & $4.0(0.12)$ & $7 / 10$ & $8 / 10$ \\
\hline 26. Explores patient's expectation or preference & $4.4(0.70)$ & $4.0(1.20)$ & $5 / 10$ & $7 / 10$ \\
\hline 27. Use easily understood questions and comments & $4.8(0.42)$ & $4.9(0.32)$ & $7 / 10$ & $10 / 10$ \\
\hline 28. Check patient's understanding of information given & $4.3(0.68)$ & $4.3(0.68)$ & $8 / 10$ & $8 / 10$ \\
\hline 29. Ask if there is anything else patient would like to discuss & $4.4(0.52)$ & $4.5(0.53)$ & $10 / 10$ & $10 / 10$ \\
\hline $\begin{array}{l}\text { 30. Provide the correct amount and type of information considering patient's } \\
\text { level of understandinglex, age, education, socio-economic status, } \\
\text { seriousness of disease) }\end{array}$ & $4.7(0.48)$ & $4.4(0.97)$ & $4 / 10$ & $7 / 10$ \\
\hline $\begin{array}{l}\text { 31. Identify additional resources and supports (family, friends, financial } \\
\text { situation) }\end{array}$ & $4.2(0.63)$ & $3.9(0.99)$ & $7 / 10$ & $8 / 10$ \\
\hline 32. Reach agreement reflecting patient's ideas and expectation & $4.7(0.48)$ & $4.5(0.53)$ & $6 / 10$ & $8 / 10$ \\
\hline 33. Ask patient's willingness and ability to follow treatment plans & $4.4(0.52)$ & $4.5(0.53)$ & $9 / 10$ & $9 / 10$ \\
\hline 34. Encourages patient to discuss any additional points, further questions & $4.2(0.63)$ & $4.5(0.53)$ & $8 / 10$ & $8 / 10$ \\
\hline 35. Closes interview by summarizing briefly & $4.2(0.63)$ & $4.2(0.63)$ & $7 / 10$ & $8 / 10$ \\
\hline 36. Discuss follow-up (e.g., next visit, plan for unexpected outcomes) & $4.7(0.48)$ & $4.1(1.30)$ & $10 / 10$ & $10 / 10$ \\
\hline
\end{tabular}

SD: Standard deviation, NS: Not significant.

a)'Yes' means 'it can be measured', 'total' stands for the total number of respondents.

고 들어주기), 14번(환자의 말에 내포되어 있는 내용과 감정

에 대해 재진술하기), 24번(문제나 질병에 대한 환자의 생각

또는 감정을 말할 수 있도록 격려하기) 항목이었다. 


\section{2. 일개 의과대학 의료대화 수업 적용 예}

이상에서 개발한 환자-의사 커뮤니케이션 모델은 2008년 2 학기 고려대학교 의학과 2학년 개설과목인 '의료대화' 수업의 교육과 학생 성취도 평가에 활용되었다. 또한 모델 각 항목의 중요도에 대한 학생 인지도 평가와 수행 자신감 자가 평가에 적용되었다. 이 수업은 9월부터 12월까지 16주, 30시간 동안 진행되었으며 표준화 환자와의 개별 면담, 소그룹 토의 및 강 의 등 다양한 수업 방법이 적용되었다. 수강학생은 총 111 명이 었고, 이 중 남학생이 74명(67\%), 여학생이 37명(33\%)이었다.

\section{1) 교육모델로 활용}

총 7개 영역, 36 개 문항으로 구성한 환자-의사 커뮤니케이 션 모델 초안의 전문가 검토에서 '의사가 갖추어야 할 핵심자 질인가에 대해서는 평균 4.0점 이하인 항목이 8개였으나 1개 항목 이외의 모든 항목에서 평균점수가 3.5점 이상이었고, '학 생이 습득해야 할 자질인가에 대해서는 36 개 항목 모두에 대 하여 필요성을 높이 인식하고 있어서 개발팀이 개발했던 초 안모델(Table 1)을 그대로 수업에 활용하였다. 즉, 초안모델 을 강의, 표준화 환자 면담, 면담에 대한 토론과 피드백을 위 한 '교육도구'로 활용하였다.

학기 초 환자-의사 커뮤니케이션의 기본개념과 면담의 전 반적인 과정과 요소에 대한 강의 후, 36 문항으로 구성된 모델 을 학생들에게 배포하고, 각 단계별 기술들을 숙지한 후 의학 면담에 임하도록 하였다. 매 표준화 환자 면담 시 특히 강조해 서 적용해야 할 기술들을 학습목표로 설정하고, 각 면담에서 2 3개 영역에 해당하는 커뮤니케이션 기술들을 단계적으로 적용할 수 있도록 수업을 구성하였다.

첫 번째 표준화 환자 면담에서는 '면담시작' 단계에 필요한 기술, 경청에 필요한 기술(환자의 말 끊지 않고 들어주기, 요 약하기 등)에 초점을 맞추어 학생들에게 면담을 하도록 교육 하였다. 이 면담은 표준화 환자와 학생의사 일대일 면담으로 진행하였고 모든 학생들의 면담장면은 비디오로 녹화하였다. 면담 녹화 1주 후에 소그룹별(각 소그룹은 학생 9 10명과 1 명의 튜터 교수로 구성)로 각 학생의 면담에 대한 동료학생 및 교수의 피드백 시간을 갖도록 하였다. 이 시간에는 각 학생 의 면담장면을 검토하고 면담 과정에서 자신이 부족하거나 잘한 커뮤니케이션 기술을 탐색하게 한 후 36 개 항목을 참고
기준으로 개선해야 할 기술과 전략에 대해 논의하게 하였다. 두 번째 면담에서는 '공감 표현하기(예: 환자의 생각 또는 말을 이해하고 있음을 말로 표현하기, 재진술하기 등)'와 '환 자의 관점 이해하기'에 필요한 기술에 맞추어 면담을 하게 하 였다. 세 번째 이후 면담에서는 '면담 시작'에서 '면담 마무리' 에 이르는 전 과정에 필요한 기술들을 면담상황에 맞추어 적 용하게 하였다. 마지막 표준화 환자 면담과정도 비디오 녹화 를 하였고 이를 학생 자신과 동료학생들과 검토하여 첫 번째 면담에 비하여 향상된 점과 아직도 개선되어야 할 점이 무엇 인지에 대하여 성찰하고 논의하게 하였다. 이 때 역시 연구자 들이 개발했던 36 개 항목으로 구성한 모델을 토대로 자기성 찰과 동료피드백을 하도록 하였다.

\section{2) 학생 중요성 인지도 및 수행 자신감 평가 도구로 활용}

수업 시작 시와 모든 수업을 마친 직후에 학생들에게 동일 한 설문조사를 시행하여 환자-의사 커뮤니케이션 모델 각 항 목에 대한 학생들의 중요성 인지도 및 수행 자신감을 평가하 였다. 36 개 각 항목이 학생들이 필수적으로 습득해야 할 자질 인지(5점: 아주 그렇다 1점: 전혀 그렇지 않다)와 현재 자신 이 수행할 수 있는 정도(5점: 아주 잘 할 수 있다 1점: 전혀 할 수 없다)를 각각 5점 척도로 답하게 하였다. 각 설문 항목 에 대하여 학생들이 정확히 이해하고 답변하는 것인지를 동 시에 확인하기 위하여 '이해 안 됨'이라는 별도의 란을 두어 표시하게 하였다.

그 결과 각 항목의 중요성에 대한 평가는 평균 3.6에서 4.8 점에 걸쳐 있었다. 중요성 면에서 4.0 이하의 평가를 받은 항 목은 수업 전 평가에서 4 개, 수업 후 평가에서 1 개에 불과하 였다. 수업 전· 후 중요성에 대한 학생들의 인식의 변화를 분 석한 결과, 36 개 전체 항목에 대한 평균점수가 수업 시작 시 4.32 (표준편차 0.38)에서 마지막 수업에 평가한 점수는 4.43 (표준편차 0.36)으로 통계적으로 유의한 변화를 나타냈다 $(\mathrm{p}<0.05)$. 각 항목별로 볼 때는 총 11 개 항목(2번, 3 번, 4 번, 5 번, 11번, 12번, 17번, 21번, 23번, 29번, 34번)에서 수업 시 작 시기보다 종료 시 평균점수가 유의하게 높았다.

각 항목을 얼마나 잘 수행할 수 있는지에 대한 학생 자가 평가에는 수업 시작 시 총 평균점수가 3.55 (표준편차 0.49)에 서 수업 종료 시 4.02 (표준편차 0.43 )로 현저한 상승을 보였 
다 $(\mathrm{p}<0.001)$ 항목별로는 33 개 항목(1번, 5 번, 33번을 제외한 나머지)에서 수업시작 시기보다 수업 종료 시 점수가 유의하 게 상승하였다.

항목에 대한 이해도 평가에 있어서는 대부분의 학생들이 잘 이해하고 있었지만, 1 개 항목(8번: 면담의 목표를 설명하거나, 필요한 경우 의견조율을 통해 목표 수립하기)에 대해서만 전 체 학생 중 20 명이 이해가 잘 안된다고 지적하였다. 나머지 35 개 항목에 대해서 '이해 안 됨에 표시한 학생은 없었다.

\section{3) 학생 성취도 평가를 위한 채점표 개발 시 활용}

수업에 대한 최종 학생 성취도 평가를 위해 표준화 환자 면 담 2개의 실기시험 사례를 개발하였다. 각 사례는 7분으로 구 성되었으며 한 개 사례는 '목과 어깨가 당기고 아픔(이하 사례 $\mathrm{A}$ 로 기술)'이었고, 다른 사례는 '나쁜 소식 전하기(이하 사례 $\mathrm{B}$ 로 기술'였다. 사례 $\mathrm{A}$ 에 대한 수행능력 평가 채점표를 먼저 개발하였고, 사례 $\mathrm{B}$ 에 대한 채점표는 사례 $\mathrm{A}$ 의 채점표와 공 통적으로 사용할 수 있는 문항을 포함하되 ‘나쁜 소식 전하기’ 의 특수한 상황에서 필요한 커뮤니케이션 기술을 평가할 수 있는 문항을 추가하여 개발하였다. 여기서는 사례 $\mathrm{A}$ 의 학생 성취도 평가에서 사용했던 채점표 개발과정과 채점방식만을 기술하였다.

첫째, 전문가 검토에서 전문가 10 명 중 5 명 이상이 '적절치 않다고 응답한 항목이나 학생들의 이해도가 낮았던 항목에 대해서 객관적인 평가가 가능한 것인지를 연구자들이 회의를 통해 재검토를 하였다. 그 결과 '환자의 주요 관심사 혹은 정 보를 관심을 가지고 들어주기(11번 항목)'는 중요한 항목이기 는 하지만 평가 시에는 10 번 문항(면담기간 동안 환자의 말을 끊지 않고 들어주기)과 구분하여 평가하기 어렵고 10 번 항목 이 11 번 항목을 포함하면서도 관찰하기에 더 적절하다고 판 단되어 11 번 항목은 채점표에서 삭제하였다. 14 번 항목(환자 의 말에 내포되어 있는 내용과 감정에 대한 재진술)의 경우, 전문가들은 평가하기 어렵다고 응답하였으나 실제 '재진술'의 정의를 잘 숙지할 경우 수행 여부에 대한 객관적 평가가 가능 한 행동(behavior)이므로 평가항목에 그대로 포함하였다. '문 제나 질병에 대한 환자의 생각 또는 감정을 말할 수 있도록 격려하기(24번 항목)'는 평가자 교육이 선행되면 충분히 측정 가능한 행동으로 판단되어 평가항목에 포함하였다. 그러나 학생들의 $20 \%$ 에서 '이해가 안 된다고 응답했던 면담의 목표
조정 및 설명하기(8번 문항)의 경우는 국내 현실에서 학생들 이 환자를 만나 면담의 목표를 협상하는 경우가 거의 없으며, 학생 수준 이상의 것으로 판단되어 평가항목에서 제외하였다 (Table 2의 28개 채점항목 참조).

둘째, 교육모델과 학생 중요성 인지도 및 수행 자신감 평가 도구에는 포함하였지만 표준화 환자 면담 수행시험의 목표, 시험사례 내용 또는 학생수준에 부합하지 않다고 판단되는 항목은 학생성취도 채점표에서 제외하였다. 즉, 수업 대상 학 생들은 임상실습 경험이 없는 2학년이고 해당 수업의 평가 목 적이 신체진찰보다는 커뮤니케이션 능력에 있었으므로 시험 내용 자체에서 신체진찰을 제외하였다. 따라서 신체진찰 시 요구되는 항목(21번 신체진찰을 할 것임을 미리 알려주고 설 명하기)은 학생 성취도 채점표에서 삭제하였다. 임상경험이 제한적인 2학년 학생들에게 숙달을 요구하기에는 부적합하다 고 연구자들이 판단한 항목(29번 항목, 합의도달에 대한 3개 항목 31 번, 32번, 33번)도 학생성취도 평가 채점표에서 제외 하였다.

셋째, 강의나 실습을 통하여 학습하는 것은 필요하지만 평 가에서는 객관적으로 명확히 구분하여 채점하기 어렵다고 판 단한 2개 항목, 즉 '환자 진술내용 요약하기(16번)'와 ‘환자 진 술내용 명료화하기(17번)'는 '환자가 진술한 내용을 요약하거 나 명료화하기'의 1 개 문항으로 합쳐서 채점표에 넣었다.

넷째, '면담 중 환자 이름을 포함한 호칭 사용하기'는 연구 자들이 판단하기에 관계수립에 있어 중요한 항목이라고 판단 하여 추가하였다. 위의 과정을 통해 총 28 개로 구성된 채점표 를 개발하였다(Table 2의 28개 채점항목 참조).

채점방식은 표준화환자 면담과정을 비디오로 녹화하고 $\mathrm{DVD}$ 로 제작하여 채점위원들에게 채점표와 함께 발송하여 각자 채점하게 하였다. 채점위원은 수업 시 튜터를 하였던 교 수 중 6 명이 담당하였고 채점위원 1인당 18 20명의 비디오를 채점하였다. 28 개 항목 각각에 대한 설명과 평가척도를 상세 히 기록한 가이드라인을 기준으로 채점하게 하였으며, 28 개 문항의 합 점수를 산출하였다.

\section{3. 환자-의사 커뮤니케이션 최종 모델}

이상의 과정을 통해 개발한 의과대학생을 위한 환자-의사 커뮤니케이션 최종 모델은 34항목으로 구성되었다(Table 2 
Table 2. A Patient-Doctor Communication Skills Model

\begin{tabular}{|c|c|c|}
\hline Items & $\begin{array}{c}\text { Assessment checklist }{ }^{\text {a) }} \\
\text { (28 items) }\end{array}$ & $\begin{array}{c}\text { Final model } \\
\text { (34 items) }\end{array}$ \\
\hline \multicolumn{3}{|l|}{ Initiating the session } \\
\hline 1. Greet patient appropriately & O & O \\
\hline 2. Ask and confirm patient's name & $\bigcirc$ & $\checkmark$ \\
\hline 3. Introduce (student) doctor's name & $\bigcirc$ & $\checkmark$ \\
\hline 4. Explain (student) doctor's role & $\bigcirc$ & \\
\hline 5. Show interest and respect & $\bigcirc$ & $\bigcirc$ \\
\hline 6. Identify and confirm problem list/issues using open-ended question & $\bigcirc$ & $\bigcirc$ \\
\hline 7. Listen attentively without interrupting patient's first statement & $\bigcirc$ & $\bigcirc$ \\
\hline \multicolumn{3}{|l|}{ Building relationship (these skills should be maintained throughout the interview) } \\
\hline 9. Demonstrate appropriate non-verbal behaviors & $\bigcirc$ & $\bigcirc$ \\
\hline 10. Attentively listen to patients' statements without interruption & $\bigcirc$ & $\bigcirc$ \\
\hline 12. Express empathy using verbal statements & $\bigcirc$ & $\times$ \\
\hline 13. Repeat patient's words or echoing & $\bigcirc$ & $\bigcirc$ \\
\hline 14. Paraphrase patient's statements (paraphrasing) & $\bigcirc$ & \\
\hline 99. Use appropriate appellation containing patient's full name & $\bigcirc$ & 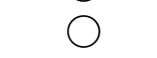 \\
\hline \multicolumn{3}{|l|}{ Gathering information } \\
\hline 15. Balanced use of open and close ended questions & $\bigcirc$ & O \\
\hline 16. Summarize patient's statements & $\sigma^{b l}$ & $\bigcirc$ \\
\hline 17. Clarify patient's statements & (1) & $\bigcirc$ \\
\hline 18. Allow patients state additional information or question & $\bigcirc$ & $\bigcirc$ \\
\hline 19. Discuss psycho-social issues & $\bigcirc$ & 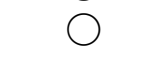 \\
\hline 20. Use transitional statements & $\bigcirc$ & 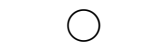 \\
\hline 21. Orient and explain physical examination in advance & $\times$ & \\
\hline 22. Structure interview in logical sequence & $\bigcirc$ & $\bigcirc$ \\
\hline \multicolumn{3}{|l|}{ Understanding patient's perspective } \\
\hline 23. Elicit patient's views of health problem(ideas, concerns) ${ }^{c l}$ & $\bigcirc$ & O \\
\hline 24. Explores influence of patient's problem or disease on his/her life $e^{c l}$ & 0 & $\bigcirc$ \\
\hline 25. Show acceptance or acknowledgement patient's idea or emotion ${ }^{c 1}$ & $\bigcirc$ & 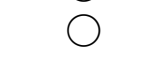 \\
\hline 26. Explores patient's expectation or preference ${ }^{c \mid}$ & $\bigcirc$ & 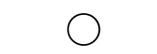 \\
\hline \multicolumn{3}{|l|}{ Sharing information } \\
\hline 27. Use easily understood questions and comments & 0 & $\bigcirc$ \\
\hline 28. Check patient's understanding of information given & $\bigcirc$ & $\bigcirc$ \\
\hline 29. Ask if there is anything else patient would like to discuss & $\times$ & ( \\
\hline \multicolumn{3}{|l|}{ Reach agreement } \\
\hline 31. Identify additional resources and supports (family, friends, financial situation) $)^{c l}$ & $\times$ & $\bigcirc$ \\
\hline 32. Reach agreement reflecting patient's ideas and expectation ${ }^{c 1}$ & $\times$ & O \\
\hline 33. Ask patient's willingness and ability to follow treatment plans ${ }^{c l}$ & $\times$ & $\bigcirc$ \\
\hline \multicolumn{3}{|l|}{ Closing the session } \\
\hline 34. Encourages patient to discuss any additional points, further questions & $\bigcirc$ & $\bigcirc$ \\
\hline 35. Summarize the visit & 0 & $\bigcirc$ \\
\hline 36. Discuss follow-up (e.g., next visit, plan for unexpected outcomes) & $\bigcirc$ & $\bigcirc$ \\
\hline
\end{tabular}

${ }^{\text {al }}$ This checklist was adapted according to the level of examinees and the characteristics of the case scenario that were used in the final examination of the authors' course, ${ }^{b}$ indicates the previous two items merged into one single item in the final version of the model, ${ }^{c}$ Indicates patient-centeredness. 
의 최종모델 34항목). 초안 모델과 비교했을 때, 3 개 항목 (Table 1의 8번, 11 번, 30번)이 삭제되었고 1개 항목(Table 2 의 99번, 면담 중 환자 이름을 포함한 호칭 사용하기)이 추가 되었다. 각 항목의 삭제 및 추가 이유는 앞에서 기술한 바와 같다.

\section{고찰}

저자들은 의과대학 학생의 의료 커뮤니케이션 교육과 평가 를 위해 면담시작, 관계수립, 정보수집, 환자관점이해, 정보공 유, 합의도달, 면담종료의 7개 영역, 총 36개로 구성한 환자의사 커뮤니케이션 모델을 개발하였고 이를 실제 수업에 활 용하였다. 학생의 성취도 평가를 위해서는 전문가 자문의견, 평가 대상의 수준, 사례의 내용을 반영하여 28 개 문항으로 구 성된 채점표를 개발, 사용하였다.

저자들이 개발한 환자-의사 커뮤니케이션 모델은 내용과 구성 면에서 선행연구에서 강조되고 있는 환자 중심적 접근, 내용과 과정의 통합적 접근, 체계적 접근 모형을 반영하고 있 으며, 특히 환자 중심적 접근을 교육 시 강조하였다. Mead \& Bower [15]에 따르면 환자 중심적 접근은 '의사가 환자의 세 계로 들어가려는 노력'으로써, 환자의 시각에서 질병(disease) 을 질환(illness)으로 보게 하고, 환자의 욕구(wants), 필요 (needs), 선호(preferences)에 부응하며, 환자에게 정보를 제 공하고 의사결정에 환자를 참여시키게 된다. 즉, 환자 중심적 진료란 환자를 개별적 요구와 생애사를 가진 한 인간으로 인 식하는 것이며, 환자-의사 관계라는 맥락에서 질환에 대한 환 자의 관점을 확인하고, 공통의 치료적 목표를 달성하도록 하 는 것이다[16,17]. 저자들이 개발한 모델에서는 환자의 감정 과 관심사/기대 파악, 환자의 질환에 대한 생각과 감정, 질환 이 환자에게 미치는 사회 심리적 영향, 환자의 가족과 사회적 지원 체계 파악을 위한 항목을 두어 학생들이 환자 중심적으 로 면담할 수 있도록 교육하였다.

또한 환자-의사 커뮤니케이션 모델을 개발함에 있어 전통 적인 생의학적 병력청취 위주의 내용중심 모형과 환자 관점 의 과정적 접근이 통합되도록 하였다. Silverman et al. [18] 은 커뮤니케이션 기술의 세 가지 형태로서 내용기술(질문과
대답을 통해 정보를 수집하고 설명을 제공하는 기술), 과정기 술(병력 청취 방법, 정보 전달 방법, 언어적· 비언어적 커뮤니 케이션 기술사용 방법, 환자와의 관계 증진 방법 등에 관한 기 술), 지각기술(의사 자신의 생각과 감정에 대한 인식 기술, 즉 자신감, 자신이 의사결정한 사항, 선입견, 태도, 의도, 기분상 태 등에 대한 인식기술)을 제시하였는데, 저자들이 개발한 모 델은 세 가지 기술이 통합되도록 구성하였다.

구조적 체계적 접근방법으로서 이 연구는 선행연구들 중 Kalamazoo Consensus의 체계에 따라 면담의 전 과정을 면 담시작, 관계수립, 정보수집, 환자관점 이해, 정보 공유, 합의 도달, 면담 종료에 이르는 순차적 구조로 구성함으로써 면담 전체 과정을 체계적으로 조망할 수 있게 하였다. 이러한 구조 는 면담 시 의사가 목적을 잃지 않고 초점을 유지하게 하며, 진행해야 할 면담의 단계를 기억할 수 있게 하고, 면담이 체계 적이고 효율적으로 이루어지게 한다[11]. 교육상황에서 환자 -의사 커뮤니케이션 모델의 구조는 단순히 암기하기에는 많 은 커뮤니케이션 기술들을 전체적, 개념적 구조를 통해 기억 하고 활용할 수 있게 한다. 즉, 구조는 면담 시작부터 종료에 이르는 전 과정을 구성하는 커뮤니케이션 기술들의 유기적 구성체계라고 할 수 있다.

전문가 자문 결과에서 전문가들은 교육모델 36 문항 중 의 사에게 필요한 핵심기술이 28 문항, 학생이 배워야 할 기술이 34 문항이라고 평가한 바 있다(5점 만점 중 4점 이상 기준). 이 러한 결과는 표준적인 환자-의사 커뮤니케이션 기술들이 의 사의 진료현장에서는 덜 요구되더라도 교육장면에서는 엄격 하게 교육되어야 함을 시사한다. 즉, 환자-의사 커뮤니케이션 수행능력 평가항목은 교육대상자가 가지고 있는 의학적 지식 의 폭과 깊이를 고려하여 선택적으로 구성한다. 임상 지식과 경험이 부족한 1,2 학년 학생들의 평가 시에는 신체검진, 치 료계획 수립, 합의도달과 같은 커뮤니케이션 기술을 제외하 고, 임상경험과 실제 환자 대면 경험이 더 많은 3,4 학년 또는 전공의의 수행능력 평가 시에는 모든 요소들을 포함시킬 수 있다. 그러나 교육모델에서는 수업의 현실 또는 평가가능성 과 관계없이 수업을 통해 학생들이 반드시 알아야 하고, 수행 할 수 있어야 하는 커뮤니케이션 기술들을 모두 포함시킨다 [19]. 표준 모델로서 이 연구에서 개발한 36문항은 특정 상황 이나 학생 또는 의사의 대상을 구별하지 않고 가능한 모든 항 
Young Hee Lee and Young-Mee Lee: Development of a Patient-Doctor Communication Skills Model for Medical Students

목을 포괄하는 원형에 가깝게 개발하였으므로 상황에 따라 사용목적에 맞게 신축성 있게 문항을 추출하여 사용할 수 있 다. 임상경험이 많은 학생들에게는 최종 모델 36항목을 모두 다 적용하여 쓸 수 있고, 임상경험이 적은 학생들에게는 채점 표에 있는 28항목을 기준으로 활용하면 된다.

앞의 연구결과에서 제시하였듯이 환자 면담 시 36 개 각 항 목의 중요성과 수행에서의 자신감을 수업 전· 후에 비교한 결 과 10 개 항목에서 학생들의 중요성에 대한 인식에 있어 유의 미한 변화를 보였고, 수행에 있어서의 자신감은 수업 전보다 수업 후에 33개 항목에서 점수가 유의미하게 상승함으로써 이 연구에서 개발한 36 개 항목의 교육 모델로서의 유용성이 입증되었다.

이 연구에서 개발한 모델은 의과대학 또는 의학전문대학원 학생들의 커뮤니케이션 교육 모델로 활용할 수 있을 것이다. 커뮤니케이션에 관한 이론과 선행 교육과정에 대한 광범위한 문헌검토 및 교수와 학생의 의견 수렴을 통하여 개발한 도구 이기는 하나, 일개 대학의 교수와 학생들의 대상으로 내용 타 당성과 유용성을 검증한 바, 일반화할 수 있는 표준적 모델을 개발하기 위해서는 국내 전문가들의 의견 수렴이 필요하다. 또한 저자들이 개발한 모델은 의과대학생을 교육 대상으로 하였기 때문에 실제 의사들의 커뮤니케이션 교육에 사용하기 위해서는 추가적 요소가 필요하다. 이 연구에서 개발한 모델 을 활용한 향후 교육과 추가 연구를 통하여 국내 상황에 적합 한 커뮤니케이션 모델을 지속적으로 발전시켜 나가야 할 것 이다.

\section{CONFLICT OF INTEREST}

None.

\section{ACKNOWLEDGEMENTS}

This research was supported by Basic Science Research Program through the National Research Foundation of Korea (NRF) funded by the Ministry of
Education, Science and Technology (KRF-2008-313E00001).

\section{REFERENCES}

1. Stewart MA. Effective physician-patient communication and health outcomes: a review. CMAJ 1995; 152: 1423-1433.

2. Beach MC, Roter DL, Wang NY, Duggan PS, Cooper LA. Are physicians' attitudes of respect accurately perceived by patients and associated with more positive communication behaviors? Patient Educ Couns 2006; 62: $347-354$.

3. Fritzsche PJ. Communication: the key to improved patient care. Radiology 2005; 234: 13-14.

4. Makoul G, Schofield T. Communication teaching and assessment in medical education: an international consensus statement. Netherlands Institute of Primary Health Care. Patient Educ Couns 1999; 37: 191-195.

5. Association of American Medical Colleges. Contemporary issues in medicine: communication in medicine. Washington, DC, USA: Association of American Medical Colleges; 1999.

6. ACGME Outcome Project [Internet]. Accreditation on Council for Graduate Medical; c2009 [cited 2009 August 10]. Available from: http://www.acgme.org/outcome.

7. Frank JR, Jabbour M, Tugwell P. Skills for the new millennium: report of the societal needs Working Group, CanMEDS 2000 Project. Ann R Coll Physicians Surg Can 1996; 29: 206-216.

8. No YG. The current situation of medical communication skills' education. Paper presented at: Korean Academy on Communication in Healthcare, Spring Conference; 2009 March.

9. Simpson M, Buckman R, Stewart M, Maguire P, Lipkin M, Novack D, Till J. Doctor-patient communication: the 
Toronto consensus statement. BMJ 1991; 303: 13851387.

10. Makoul G. The SEGUE framework for teaching and assessing communication skills. Patient Educ Couns 2001; 45: 23-34.

11. Kurtz S, Silverman J, Benson J, Draper J. Marrying content and process in clinical method teaching: enhancing the Calgary-Cambridge guides. Acad Med 2003; 78: 802-809.

12. Makoul G. Essential elements of communication in medical encounters: the Kalamazoo consensus statement. Acad Med 2001; 76: 390-393.

13. ACGME Outcome Project: General Competencies [Internet]. Accreditation on Council for Graduate Medical; c1999 [cited 2005 March 4]. Available from: http://www.acgme.org/outcome/comp/compMain.asp.

14. Lee YH, Lee YM, Kim BS. The relationship between personality types, communication skills and learning attitudes in premedical students. Korean J Med Educ 2008; 20: 177-187.

15. Mead N, Bower P. Patient-centredness: a conceptual framework and review of the empirical literature. Soc Sci Med 2000; 51: 1087-1110.

16. Aita V, Mcllvain H, Backer, E. McVea, K, Crabtree B. Patient-centered care and communication in primary care practice: what is involved? Patient Educ Couns 2005; 58: 296-304.

17. Brown JB, Lent B, Stirling A, Takhar J, Bishop J. Caring for seriously mentally ill patients. Qualitative study of family physicians' experiences. Can Fam Physician 2002; 48: 915-920.

18. Silverman J, Kurtz S, Draper J. Skills for communicating with patients. Oxford, UK: Radcliffe Publishing; 2005.

19. Rider EA, Hinrichs MM, Lown BA. A model for communication skills assessment across the undergraduate curriculum. Med Teach 2006; 28: el27-el34. 